\title{
Perinatal Mortality in Nigeria: Do Place of Delivery and Delivery Assistants Matter?
}

\author{
Samuel Oji Oti ${ }^{\mathrm{a}, \mathrm{b}^{*}}$ and Clifford Odimegwu ${ }^{\mathrm{c}}$
}

${ }^{a}$ School of Public Health, University of Witwatersrand, Johannesburg, South Africa

${ }^{b}$ African Population and Health Research Center, Nairobi, Kenya

${ }^{c}$ Programme in Demography and Population Studies, University of Witwatersrand, Johannesburg, South Africa

\begin{abstract}
:
Background: Studies in developed countries have shown that deliveries which occur at home and under the supervision of unskilled attendants present a high risk of perinatal death. However, it is unclear, especially in sub- Saharan Africa (SSA) where studies are limited, on precisely how these factors may influence perinatal mortality. This is particularly of interest considering that majority of births in SSA occur at home under the supervision of unskilled attendants and perinatal mortality in the sub-region is about five times that of the developed world. This study aims to determine the extent to which these factors influence perinatal mortality in Nigeria in order to inform maternal and child health policy decisions.

Methods: This study uses secondary data from the 2003 Nigerian Demographic and Health Survey. Logistic regression analysis was used to determine the association of place of delivery and delivery assistants with perinatal mortality while controlling for other known risk factors.

Results: Of the 5783 live singleton births that were analyzed, 194 were perinatal deaths giving an estimated perinatal mortality rate (PNMR) of 72.4 per 1000 live births. However, the results show that place of delivery and delivery assistants were not significantly associated with perinatal mortality in Nigeria.

Conclusions: In this study, place of delivery and delivery assistants are not critical predictors of perinatal mortality in Nigeria. However in view of the high PNMR found in this study, we recommend improved skilled attendance and institutional delivery rates as part of efforts for better maternal and child health in developing countries.
\end{abstract}

Key Words: Perinatal mortality, home births, unskilled deliveries, Nigeria.

\section{BACKGROUND}

Perinatal mortality -that is deaths in the first week of life including still births- is at an unacceptably high level in developing countries, especially those in sub-Saharan Africa (SSA) [1]. Global estimates show that the perinatal mortality rate (PNMR) in developed regions of the world is about 10 per 1000 live births compared with 50 per 1000 live births in less developed regions of the world [1]. These figures are particularly troubling because the PNMR is known to be a key health status indicator of a community [2]. Specifically, it is an important indicator of the quality of obstetric and pediatric care available in any setting but at the same time it is a major contributor to overall childhood mortality [3].

Reducing childhood mortality levels by two-thirds by the year 2015 is one of the Millennium Development Goals (MDG-4) set by the United Nations [4]. Recent evidence

*Address correspondence to this author at the African Population and Health Research Center, Longonot Road, Upper Hill P.O. Box 10787, GPO 00100, Nairobi, Kenya; Tel: +254 20 2720400; Fax: +254 20 2720380; E-mail: soti@aphrc.org suggests that neonatal mortality -death of a newborn within the first 4 weeks of life-contributes more than $50 \%$ of infant mortality globally. Furthermore, of all neonatal deaths, three-quarters occur in the perinatal period. Therefore, achieving MDG-4 will require a substantial reduction in perinatal deaths in high mortality countries $[5,6]$. Unfortunately, despite evidence of gains in reducing childhood mortality globally, deaths in the perinatal period have shown the least progress and hence threaten to reverse these gains [1].

In 2000, the World Health Organisation (WHO) estimated the number of perinatal deaths globally to be greater than 6.3 million, with about $98 \%$ of these deaths occurring in low and middle-income countries [1, 6]. Nigeria is a lowincome country that has experienced a surge in perinatal deaths over the past few decades. An earlier estimate of perinatal deaths in Nigeria was thought to be around 30 per 1000 live births in 1990 [7]. This figure almost tripled to 86 per 1000 live births by the year 2000 [1]. This high level of perinatal mortality in Nigeria means that the country may be unable to attain MDG-4 by the year 2015 .

The level of perinatal mortality in a community is said to be associated with the proportion of births that take place 
at a health facility and the coverage of skilled attendance at birth. Countries where skilled attendance and institutional delivery rates are low usually have a high PNMR [6]. For instance, in Nigeria, only $35.2 \%$ of live births are delivered with the supervision of a skilled attendant and Nigeria has a very high PNMR of 86 per 1000 live births [1, 8].

Whereas in the United States (U.S.), $99.3 \%$ of live births are assisted by a skilled attendant [9] and the PNMR is only 7 per 1000 live births [1]. Therefore, improving the levels of skilled attendance at birth (delivery assistants) and increasing the numbers of births that occur in a health facility rather than at home (place of delivery) in countries where PNMR is high may lead to better perinatal health outcomes and ultimately reduce childhood mortality in line with the MDGs.

In the developed world, there is a sizable body of literature that has examined the roles of place of delivery and delivery assistants in determining perinatal mortality [1014]. On one hand, it is quite clear in the literature that unsupervised deliveries and those supervised by unskilled persons carry a significantly high risk of perinatal mortality. On the other hand it remains unclear whether delivery in a hospital is in itself safer than delivery at home under the supervision of a skilled attendant [15]. In other words, the debate in the developed world is focused on whether home deliveries are safer than institutional deliveries, considering that almost all births, whether occurring in a hospital or at home, are at least supervised by a skilled attendant.

However in the developing world where perinatal mortality rates remain high, most births occur at home and are supervised by unskilled persons such as untrained traditional birth attendants (TBA) and relatives. Very few studies have attempted to investigate whether or not place of birth and delivery assistants are critical predictors of perinatal mortality in developing countries. Where available, these studies have often only examined the effect of place of delivery on perinatal mortality without considering the type of delivery assistant [16]. Other studies have looked at deliveries occurring at home and supervised by an unskilled person and compared the perinatal outcome with deliveries in a health facility $[17,18]$. Such studies ignore the fact that even in developing countries some home deliveries are supervised by trained persons such as midwives or nurses. It therefore remains unclear in the context of developing countries what the precise roles of place of delivery and delivery assistants are in determining perinatal mortality. This study therefore aims to determine the extent to which place of delivery and delivery assistants predict perinatal mortality in the Nigerian context.

\section{METHODOLOGY}

\section{Data Source}

Data from the 2003 Nigerian Demographic and Health Survey (NDHS 2003) was used for this analysis. The complete methodology employed in the NDHS 2003 is described in the final survey report [8]. Briefly, the NDHS

2003 is the third national demographic and health survey (DHS) conducted in Nigeria by the National Population Commission (NPC) and Macro International Incorporated. It is based on a nationally representative sample of 7864 households. All women aged 15-49 years in these households were sampled to be individually interviewed. Hence, 7985 women were sampled, out of which $95 \%$ of them were successfully interviewed. The NDHS 2003 collected information on fertility levels and preferences, awareness and use of family planning methods, maternal and child health, breastfeeding practices, nutritional status of women and young children, childhood mortality, use of bed nets, female genital cutting, marriage, sexual activity, and awareness and behaviour regarding HIV/AIDS and other sexually transmitted infections in Nigeria.

\section{Estimating the Number of Births}

There were a total of 6029 observations in the dataset representing the total number of live births born to the interviewed mothers in the 5 years preceding the NDHS 2003. Out of this number, 246 live births were excluded because they were outcomes of multiple births. Therefore a total of 5783 live births were analyzed in this study, out of which 194 were deaths that occurred within the first seven days of life. These deaths do not include still births as this information was impossible to ascertain in the NDHS 2003.

\section{Exposure and Outcome Measures}

Table 1 shows the operationalization of the variables presented in this paper. The main explanatory variable is a composite of place of delivery and delivery assistants and is categorized as follows: "Skilled institutional deliveries", "Skilled home deliveries", "Unskilled home deliveries" and "Unskilled institutional deliveries". We defined the term "skilled" as births supervised by doctors and or nurses/midwives; while "unskilled" refers to births assisted by traditional birth attendants and relatives/friends. The term "institutional" refers to births occurring in a health facility including public and private hospitals, clinics, health centers and health posts. While "home" refers to deliveries occurring outside a health facility, usually in a place of residence.

Other known controlling factors included in this study are maternal socio-economic and bio-demographic variables such as Maternal age at birth, Highest level of education of mother, Region (Geo-political location), Place of residence (rural/urban), Religion, Wealth index, Maternal parity, and number of Antenatal visits in pregnancy. Variables related to the child include Birth size (as reported subjectively by the mother) and Gender of child. Note that birth size is used as a proxy for birth weight since only about $10 \%$ of the respondents in the NDHS 2003 provided actual figures for birth weight. These factors have been shown in previous studies to be associated with perinatal mortality $[12,13,16$, 18-24].

The outcome variable used was the survival status of births by the first week of life -perinatal mortality. That is, each of the babies born to the interviewed women were categorized as alive or dead depending on whether or not the newborn survived the first seven days of life. Those babies who died within this period were compared to those who survived the same period. Note that this variable does not include information on still births which is not available in the primary dataset. Hence all analysis performed using this variable excludes still births. 
Table 1. Definition of Variables

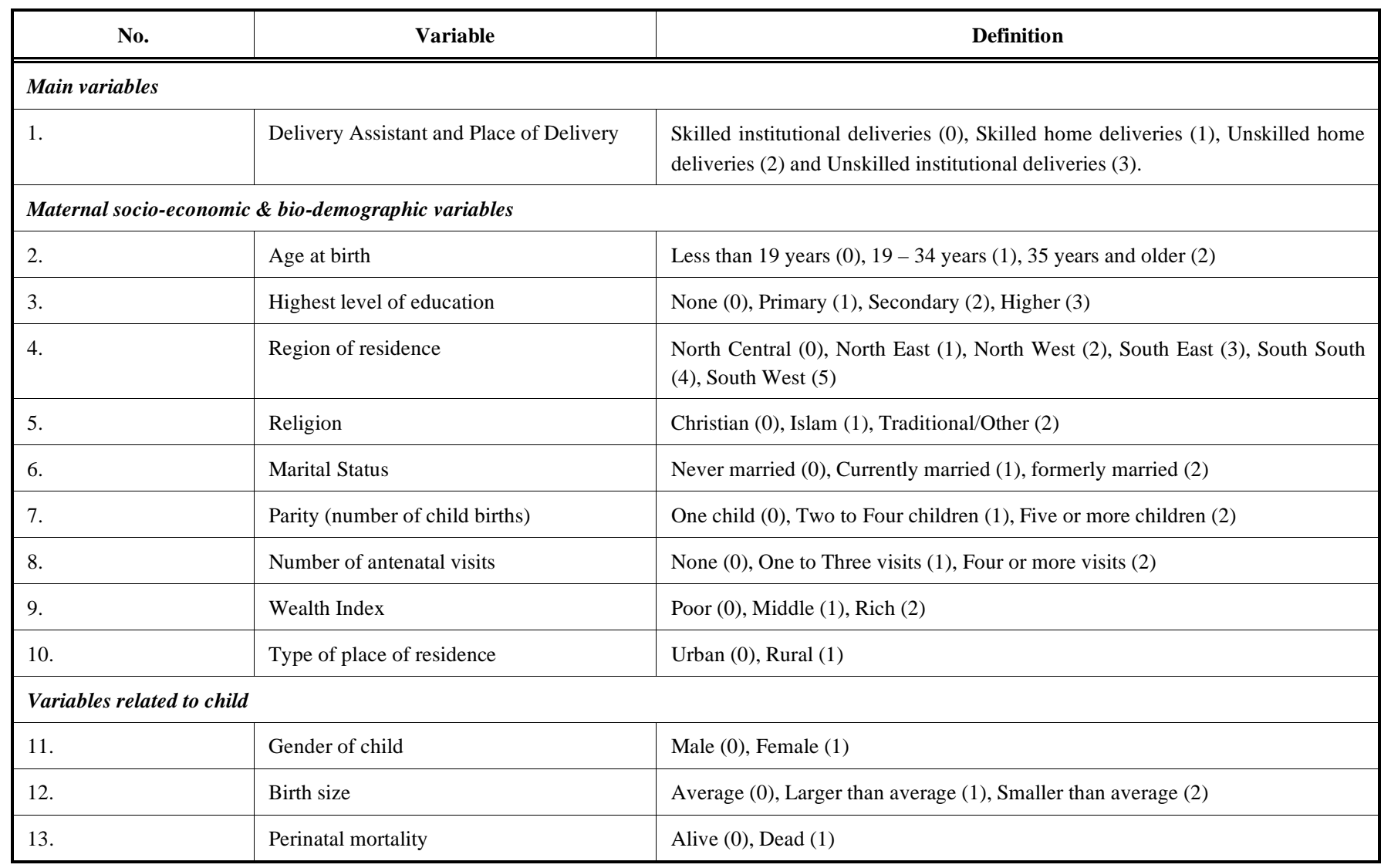

\section{Statistical Analysis}

All data analysis was performed using STATA 10 statistical software. We used cross tabulations to describe and compare maternal and child characteristics by our main explanatory variable. This was followed by a bivariate analysis to examine the relationship between each variable of interest and the outcome variable -perinatal mortality (coded as zero if child survived the perinatal period and one if child died within this period). The final stage involved the use of stepwise logistic regression modeling to estimate the effect of place of delivery and delivery assistants on perinatal mortality, having controlled for the other potential risk factors.

\section{Findings}

The main objectives of this study were to estimate the level of perinatal mortality in Nigeria and to examine the influence of place of delivery and delivery assistants on perinatal mortality using data from the NDHS 2003. Out of 5783 singleton live births that occurred in the five years preceding the survey, there were 194 deaths before the $7^{\text {th }}$ day of life giving an early neonatal mortality rate (ENMR) of 33.5 per 1000 live births. However, to determine the perinatal mortality rate (PNMR) we needed to estimate the still births rate (SBR), which as previously mentioned is unavailable in the primary data source. Hence, to estimate the SBR, we used formulae adopted by the WHO for countries where information on still births is lacking or inadequate [1].
The formula used is $\mathbf{S B R} / \mathbf{E N M R}=\mathbf{K}$; Where $\mathrm{K}$ is a constant value unique to each of the six world regions: for Africa, WHO estimates $\mathrm{K}$ to be 1.2. The SBR is computed by multiplying the ENMR by $\mathrm{K}$ and therefore the SBR for Nigeria is 40.2 or $(33.5 * 1.2)$ per 1000 live births. The total number of still births (SBN) given the number of live births in the study population is 242 or $(40.2 * 5783) /(1000-40.2)$. The total number of births (TNB) is given by $(\mathrm{SBN}+\mathrm{LB})$ and is therefore $6025(242+5783)$. The PNMR which is given by $(\mathrm{SBN}+\mathrm{LB}) /(\mathrm{TNB})$ is equal to 72.4 per 1000 births, that is $(242+194) / 6025 * 1000$.

\section{Characteristics of Births by Place of Delivery and Deliv- ery Assistants}

Unskilled home deliveries accounted for majority (60\%) of the births in this study. Skilled institutional deliveries accounted for $34 \%$ while skilled home deliveries and unskilled institutional deliveries accounted for $4 \%$ and $2 \%$ of births respectively. Table 2 shows the distribution of selected maternal and child characteristics by place of delivery and delivery assistants. Unskilled home deliveries had the largest proportions of mothers living in rural areas (76\%), who were poor $(59 \%)$, who had no education (70.4\%), and who had more than 5 previous live births $(45 \%)$. Also, unskilled home deliveries had the lowest proportion of mothers who had 4 or more antenatal visits in pregnancy $(28 \%)$. Skilled institutional deliveries had the highest proportion of births occurring in urban areas (53\%), mothers who had 4 or more antenatal visits $(85.6 \%)$, mothers who were educated above secondary level (54\%), and 
Table 2. Maternal and Child Characteristics by Place of Delivery and Delivery Assistant

\begin{tabular}{|c|c|c|c|c|c|c|c|c|c|}
\hline & \begin{tabular}{|c|} 
Skilled \\
Institutional Deliveries \\
(n)
\end{tabular} & $\%$ & $\begin{array}{c}\text { Skilled } \\
\text { Home Deliveries } \\
\text { (n) }\end{array}$ & $\%$ & $\begin{array}{c}\text { Unskilled } \\
\text { Home } \\
\text { Deliveries (n) }\end{array}$ & $\%$ & $\begin{array}{l}\text { Unskilled } \\
\text { Institutional } \\
\text { Deliveries } \\
\text { (n) }\end{array}$ & $\%$ & p-Value \\
\hline \multicolumn{10}{|l|}{ Variables } \\
\hline Maternal age at birth & & & & & & & & & $<0.0001$ \\
\hline$<19$ years & 89 & 4.6 & 25 & 9.9 & 259 & 7.5 & 4 & 5.2 & \\
\hline $20-34$ years & 1380 & 71.4 & 154 & 61.1 & 2448 & 71.0 & 54 & 70.1 & \\
\hline \multirow[t]{2}{*}{$35+$ years } & 463 & 24.0 & 73 & 29.0 & 740 & 21.5 & 19 & 24.7 & \\
\hline & 1932 & 100 & 252 & 100 & 3447 & 100 & 77 & 100 & \\
\hline North east & 245 & 12.7 & 66 & 26.2 & 1098 & 31.9 & 8 & 10.4 & \\
\hline North west & 206 & 10.7 & 48 & 19.0 & 1466 & 42.5 & 6 & 7.8 & \\
\hline South east & 356 & 18.4 & 28 & 11.1 & 86 & 2.5 & 5 & 6.5 & \\
\hline South south & 273 & 14.1 & 35 & 13.9 & 201 & 5.8 & 26 & 33.8 & \\
\hline \multirow[t]{2}{*}{ South west } & 427 & 22.1 & 28 & 11.1 & 116 & 3.4 & 17 & 22.1 & \\
\hline & 1932 & 100 & 252 & 100 & 3447 & 100 & 77 & 100 & \\
\hline Place of residence & & & & & & & & & $<0.0001$ \\
\hline No education & 345 & 17.9 & 94 & 37.3 & 2427 & 70.4 & 18 & 23.4 & \\
\hline primary & 551 & 28.5 & 84 & 33.3 & 711 & 20.6 & 32 & 41.6 & \\
\hline secondary & 852 & 44.1 & 72 & 28.6 & 294 & 8.5 & 24 & 31.2 & \\
\hline \multirow[t]{2}{*}{ higher } & 184 & 9.5 & 2 & 0.8 & 15 & 0.4 & 3 & 3.9 & \\
\hline & 1932 & 100 & 252 & 100 & 3447 & 100 & 77 & 100 & \\
\hline Marital status & & & & & & & & & $<0.0001$ \\
\hline Never married & 73 & 3.8 & 2 & 0.8 & 30 & 0.9 & 2 & 2.6 & \\
\hline Currently & 1780 & 92.1 & 241 & 95.6 & 3306 & 95.9 & 72 & 93.5 & \\
\hline \multirow[t]{2}{*}{ Formerly } & 79 & 4.1 & 9 & 3.6 & 111 & 3.2 & 3 & 3.9 & \\
\hline & 1932 & 100 & 252 & 100 & 3447 & 100 & 77 & 100 & \\
\hline Gender of child & & & & & & & & & 0.16 \\
\hline Male & 1002 & 51.9 & 127 & 50.4 & 1721 & 49.9 & 47 & 61.0 & \\
\hline
\end{tabular}


Table 2. contd....

\begin{tabular}{|c|c|c|c|c|c|c|c|c|c|}
\hline & $\begin{array}{c}\text { Skilled } \\
\text { Institutional Deliveries } \\
\text { (n) }\end{array}$ & $\%$ & $\begin{array}{c}\text { Skilled } \\
\text { Home Deliveries } \\
\text { (n) }\end{array}$ & $\%$ & $\begin{array}{c}\text { Unskilled } \\
\text { Home } \\
\text { Deliveries (n) }\end{array}$ & $\%$ & $\begin{array}{c}\text { Unskilled } \\
\text { Institutional } \\
\text { Deliveries } \\
\text { (n) }\end{array}$ & $\%$ & p-Value \\
\hline \multirow[t]{2}{*}{ Female } & 930 & 48.1 & 125 & 49.6 & 1726 & 50.1 & 30 & 39.0 & \\
\hline & 1932 & 100 & 252 & 100 & 3447 & 100 & 77 & 100 & \\
\hline Wealth Index & & & & & & & & & $<0.0001$ \\
\hline Poor & 417 & 21.6 & 72 & 28.6 & 2049 & 59.4 & 27 & 35.1 & \\
\hline Middle & 800 & 41.4 & 131 & 52.0 & 1252 & 36.3 & 33 & 42.9 & \\
\hline Rich & 715 & 37.0 & 49 & 19.4 & 146 & 4.2 & 17 & 22.1 & \\
\hline Christian & 1276 & 66.0 & 118 & 46.8 & 734 & 21.3 & 49 & 63.6 & \\
\hline Islam & 637 & 33.0 & 131 & 52.0 & 2621 & 76.1 & 27 & 35.1 & \\
\hline \multirow[t]{2}{*}{ Traditional/other } & 19 & 1.0 & 3 & 1.2 & 87 & 2.5 & 1 & 1.3 & \\
\hline & 1932 & 100 & 252 & 100 & 3442 & 100 & 77 & 100 & \\
\hline Parity & & & & & & & & & $<0.0001$ \\
\hline primiparous & 348 & 18.0 & 45 & 17.9 & 330 & 9.6 & 9 & 11.7 & \\
\hline no visit & 36 & 2.8 & 24 & 14.5 & 1161 & 55.3 & 15 & 30 & \\
\hline less than 4 & 146 & 11.5 & 25 & 15.2 & 347 & 16.5 & 5 & 10 & \\
\hline \multirow[t]{2}{*}{4 or more } & 1086 & 85.6 & 116 & 70.3 & 593 & 28.2 & 30 & 60 & \\
\hline & 1268 & 100 & 165 & 100 & 2101 & 100 & 50 & 100 & \\
\hline Birth size & & & & & & & & & $<0.0001$ \\
\hline Average & 811 & 42.2 & 108 & 43.2 & 1500 & 43.9 & 33 & 42.9 & \\
\hline Larger than average & 880 & 45.8 & 91 & 36.4 & 1392 & 40.8 & 36 & 46.8 & \\
\hline \multirow[t]{2}{*}{ Smaller than average } & 232 & 12.1 & 51 & 20.4 & 522 & 15.3 & 8 & 10.4 & \\
\hline & 1923 & 100 & 250 & 100 & 3414 & 100 & 77 & 100 & \\
\hline
\end{tabular}

*Chi-square p-value

also had the lowest proportion of mothers who were poor $(22 \%)$.

Skilled home deliveries had the highest proportions of mothers aged 35 years or older at birth (29\%) and the highest proportion of babies whose birth size was reported as below average or small by their mothers (20.4\%). Unskilled institutional deliveries had the largest proportion of mothers who had 2- 4 previous live births (56\%) and the lowest proportion of babies whose birth size was reported as below average or small by their mothers (10.4\%). All these differences in characteristics by place of delivery and 
delivery assistants were statistically significant. However, there was no statistical difference in the gender of the child by place of birth and delivery assistants.

Table 3 shows that neither unskilled home deliveries (unadjusted OR 1.04, 95\% CI 0.73 - 1.48) nor unskilled institutional deliveries (unadjusted OR 1.68, 95\% CI 0.62 4.59) were significantly associated with a higher risk of perinatal deaths in comparison to skilled institutional deliveries. Also, skilled home deliveries did not have a significantly higher risk of perinatal deaths in comparison to skilled institutional deliveries (unadjusted OR 1.14, 95\% CI 0.52 - 2.49). However, births in rural areas (unadjusted OR 1.57, 95\% CI 1.07 - 2.32), babies whose birth size was smaller than average (unadjusted OR 1.55, 95\% CI 1.05 2.31) and those whose mothers practiced "traditional/other" religion (unadjusted OR 5.12, 95\% CI 3.14 - 8.33) were all significantly associated with an increased risk of perinatal deaths. On the other hand, female babies (unadjusted OR $0.56,95 \%$ CI $0.41-0.77$ ) and those born to "rich" mothers had a significantly lower risk of perinatal deaths (unadjusted OR 0.43, 95\% CI $0.25-0.75$ ).

In the multivariate analysis shown in Table 4, we fit our main explanatory variable representing place of delivery and delivery assistants into a final model while controlling for the risk factors that were significantly associated $(\mathrm{p}<0.05)$ with perinatal mortality in the unadjusted analysis. Place of delivery and delivery assistants remained non-significant in this model while births in rural areas, female babies, being smaller than average in size at birth, and being born to a mother who practiced "traditional/other" religion remained significantly associated with perinatal mortality. However, being born to a rich mother was no longer a significant risk factor in the adjusted model.

\section{DISCUSSION}

This study purposed to estimate the level of perinatal mortality in Nigeria and to examine the role of place of delivery and delivery assistants in determining perinatal mortality, while taking other selected risk factors into consideration. Using the NDHS 2003 as our data source, we obtained an ENMR of 33.5 per 1000 live births and an estimated PNMR of 72.4 per 1000 live births. We did not find any significant association between our main explanatory variable - place of delivery and delivery assistants- with perinatal mortality. However, other factors such as being a female child, religion of the mother, size of the child at birth and type of place of residence (rural versus urban) were found to be significantly associated with perinatal mortality.

The lack of association between place of delivery and delivery assistants with perinatal mortality is inconsistent with previous studies $[10,12,18]$ and is especially surprising for a developing country like Nigeria where most deliveries occur at home and are not supervised by a skilled attendant [25]. In the developed world where most deliveries occur at a health facility and are attended by skilled health personnel, the above results will not be unusual [14]. One possible explanation for this result may be that majority of those who deliver at a health facility only do so if there are complications in labour by which time the health of the fetus has been seriously compromised. If this is combined with a lack of high quality perinatal care units as is the case in most public health facilities in Nigeria, the result may be a level of perinatal mortality in skilled institutional deliveries that is not very different from unskilled home delivery rates.

Another explanation may be that perhaps a good number of the "unskilled" persons such as TBA who attend to majority of births in Nigeria are in fact really good at what they do and have succeeded in avoiding significant differences in their perinatal death rates. Some previous studies in Nigeria revealed that one of the reasons why women in Nigeria patronized TBA was simply due to their positive experiences hey have had successful deliveries in the hands of TBA [26, 27]. However, these studies emphasize that the training, retraining and monitoring of TBA is crucial to ensure that the quality of services they offer are at an acceptable standard of safe birth practices.

We however found some other factors that were significantly associated with perinatal mortality. Firstly, we found that female children had a lower risk of dying in the perinatal period compared to males. It has been suggested that male children are more prone to perinatal deaths than females for biological reasons [24]. By contrast, some other studies have found a higher risk of perinatal deaths in females than males. However, these studies justified their findings by arguing that gender preference was practiced in their study populations $[28,29]$. There is no evidence to suggest that gender preference is practiced in Nigeria at a general level. Thus we can conclude that natural selection which gives female children the survival edge over males at this early stage of life is what prevails in the Nigerian context.

We also found that being born to a mother who practiced "traditional/other" religion was found to be significantly associated with an increased risk of perinatal death. The influence of religion on perinatal mortality may be linked to the beliefs and myths they may have concerning child birth. This was the case with the Faith Assembly people in Indiana, U.S., who believed that child bearing was an act of God not to be interfered with [12]. Unfortunately, this group had a perinatal mortality rate that was thrice that of the general population. We explored this association further by introducing an interaction term between religion and gender of the child on our final model (results not shown). We found that female children who were born to mothers who practiced "traditional/other" religion had a higher risk of perinatal deaths compared to male children born to "Christian" mothers (results not shown). It is difficult to say whether or not this finding reflects gender preference among the subgroup of traditionalists and further qualitative research may be useful.

Children who were reported to be "smaller than average" in size at birth, were also found to have a significantly higher risk of perinatal deaths than those who were average in size. This may reflect the increased susceptibility of low birth weight babies to infections and other abnormalities $[19,30]$. The prevailing argument is that low birth weight is a frequent intermediate factor linking other risk factors such as socioeconomic status to perinatal mortality [20, 30]. While this may be true in our study as well, caution must be exercised because we used a subjective measure of birth size as a proxy for birth weight. 
Table 3. Factors Associated with Perinatal Mortality

\begin{tabular}{|c|c|c|c|c|c|}
\hline Variables & $\mathbf{n}_{\dagger}^{\dagger}$ & $\mathbf{N} \neq$ & $\%$ & $\begin{array}{l}\text { Crude Odds Ratio } \\
\qquad(95 \% \text { CI })\end{array}$ & P-value \\
\hline \multicolumn{6}{|l|}{ Place of delivery and delivery assistants } \\
\hline Skilled institutional deliveries & 61 & 1932 & 3.2 & 1 & \\
\hline Skilled home deliveries & 9 & 252 & 3.6 & $1.13(0.52-2.49)$ & 0.75 \\
\hline Unskilled home deliveries & 113 & 3447 & 3.3 & $1.04(0.73-1.48)$ & 0.83 \\
\hline Unskilled institutional deliveries & 4 & 77 & 5.2 & $1.68(0.62-4.59)$ & 0.31 \\
\hline \multicolumn{6}{|l|}{ Maternal age at birth } \\
\hline$<19$ years & 19 & 381 & 5.0 & 1 & \\
\hline $20-34$ years & 128 & 4084 & 3.1 & $0.62(0.35-1.07)$ & 0.09 \\
\hline $35+$ years & 47 & 1318 & 3.6 & $0.71(0.39-1.25)$ & 0.24 \\
\hline \multicolumn{6}{|l|}{ Place of residence } \\
\hline Urban & 50 & 2024 & 2.5 & 1 & \\
\hline Rural & 144 & 3759 & 3.8 & $1.57(1.07-2.32)$ & 0.022 \\
\hline \multicolumn{6}{|l|}{ Gender of child } \\
\hline Male & 125 & 2940 & 4.3 & 1 & \\
\hline Female & 69 & 2843 & 2.4 & $0.56(0.41-0.77)$ & $<0.0001$ \\
\hline \multicolumn{6}{|l|}{ Wealth Index } \\
\hline Poor & 108 & 2614 & 4.1 & 1 & \\
\hline Middle & 69 & 2239 & 3.1 & $0.74(0.53-1.03)$ & 0.07 \\
\hline Rich & 17 & 930 & 1.8 & $0.43(0.25-0.75)$ & 0.003 \\
\hline \multicolumn{6}{|l|}{ Religion } \\
\hline Christian & 74 & 2212 & 3.3 & & \\
\hline Islam & 103 & 3453 & 3.0 & $0.89(0.63-1.25)$ & 0.5 \\
\hline Traditional/other & 17 & 113 & 15.0 & $5.12(3.14-8.33)$ & $<0.0001$ \\
\hline \multicolumn{6}{|l|}{ Maternal parity } \\
\hline primiparous & 31 & 734 & 4.2 & 1 & \\
\hline $2-4$ births & 77 & 2712 & 2.8 & $0.66(0.43-1.02)$ & 0.06 \\
\hline$\geq 5$ births & 86 & 2337 & 3.7 & $0.87(0.57-1.31)$ & 0.49 \\
\hline \multicolumn{6}{|l|}{ Birth size } \\
\hline Average & 81 & 2458 & 3.3 & 1 & \\
\hline Larger than average & 61 & 2412 & 2.5 & $0.76(0.56-1.03)$ & 0.08 \\
\hline Smaller than average & 41 & 815 & 5.0 & $1.55(1.05-2.31)$ & 0.03 \\
\hline
\end{tabular}

$\dagger$ Number of deaths within the first seven days of life.

\$ Total number of live births 
Table 4. Multivariate Analysis for Perinatal Mortality

\begin{tabular}{|c|c|c|}
\hline Variables & $\begin{array}{l}\text { Adjusted odds } \\
\text { Ratio }(95 \% \text { CI })\end{array}$ & P-value \\
\hline Skilled institutional deliveries & 1 & \\
\hline Skilled home deliveries & $1.01(0.44-2.26)$ & 0.99 \\
\hline Unskilled institutional deliveries & $1.51(0.53-4.32)$ & 0.44 \\
\hline \multicolumn{3}{|l|}{ Place of residence } \\
\hline Urban & 1 & \\
\hline Male & 1 & \\
\hline Female & $0.57(0.42-0.78)$ & $<0.0001$ \\
\hline \multicolumn{3}{|l|}{ Wealth Index } \\
\hline Poor & 1 & \\
\hline Middle & $0.89(0.63-1.27)$ & 0.53 \\
\hline Rich & $0.58(0.31-1.08)$ & 0.1 \\
\hline Average & 1 & \\
\hline Larger than average & $0.76(0.56-1.03)$ & \\
\hline Smaller than average & $1.56(1.05-2.33)$ & $\mathbf{0 . 0 3}$ \\
\hline
\end{tabular}

Finally, we also found that rural dwellers had a higher risk of perinatal deaths when compared to urban residents. This is supported by several studies [21, 22, 30], which generally attribute this finding to better access to perinatal care facilities in the urban areas reflecting social inequalities between the two groups.

\section{LIMITATIONS}

The quality of any DHS data depends on the completeness with which births and deaths are reported. Deaths in the first week of life are often anonymous in that the new born die and are quickly buried before they are even named. This often blurs information on these deaths and the circumstances surrounding some of them. Hence the possibility of selective under-reporting of perinatal deaths is a real threat to the data quality of this study. In order to assess if there has been selective under-reporting, the DHS uses the ratio of deaths under 7 days to all neonatal deaths as an indicator. If this ratio (expressed as a percentage) is unusually low, then it is very likely that selective under- reporting of perinatal deaths has occurred. In the case of the NDHS 2003, this ratio was quite high $-74 \%$ for the period $0-4$ years preceding the study [8]. Hence we can conclude that although selective under-reporting of perinatal deaths was a potential limitation of our study, this was not the found to be the case.

Another major limitation of our study is the issue of uncontrolled confounding. For example, pregnancy and labour complications are a strong confounder for perinatal deaths [31]. Home deliveries and those assisted by unskilled persons are associated with a high risk of labour complications. And labour complications, which are a risk with every preg- 
nancy, may be associated with increased risk of perinatal death. Some studies categorize each pregnancy by risk status and have found associations with place of delivery and perinatal mortality among high risk pregnancies but not necessarily low risk pregnancies [18]. However, full and accurate accounts of pregnancy and or labour complications are not available in the NDHS 2003 and therefore this potential confounder could not be included in our analysis.

Also, we found that information in our data source on still births is unclear -no distinction was made in the primary data source as to whether those pregnancies which did not result in live births were due to abortions, miscarriages or still births. Therefore the SBR in this study was estimated using a methodology developed by the WHO. This involved the use of regional estimates of the SBR/PNMR ratio to calculate the SBR in countries where no data on still births are available [1]. While the WHO assures that every effort has been made to arrive at reliable and balanced estimates, it also reiterates that it is not possible to calculate precise mortality rates, because reliable population-based data are not available for all countries and for all years. Nevertheless, the WHO emphasizes that regional estimates should be regarded as the best estimates possible on the basis of the information available.

\section{CONCLUSION}

Our study did not find any effect of place of delivery and delivery assistants on perinatal mortality. This lack of association may be due to the limitations of our study previously described. However, we found a PNMR in our study that is comparable to existing estimates and which by every standard is very high.

We therefore recommend that as far as health policy and planning is concerned, the Nigerian government and its development partners need to do more in order to attain significant and sustained improvement in maternal and child health and especially perinatal health. One of the United Nations MDG indicators in this regard is the proportion of deliveries supervised by a skilled attendant and we believe that the reported proportion of less than $40 \%$ for skilled delivery rates in Nigeria is unacceptably low. However, skilled delivery rates and institutional delivery rates go hand in hand. Health workers cannot be trained and retained in a vacuum. Therefore, improved skilled and institutional delivery rates can be increased via building and equipping accessible primary health care facilities and training more health personnel to attend to these facilities especially in the rural areas. Retaining a skilled health workforce especially in rural areas is a challenge for many developing countries. Hence, incentives to motivate and retain rural health workers may be necessary. These incentives may include but are not limited to financial rewards, availability of career development opportunities, access to continuing education, and service recognition/appreciation.

Although reducing perinatal mortality is only one aspect in the drive to reduce childhood mortality by two-thirds in 2015 in line with MDG-4, it will be an essential step which must be taken if sustainable progress is to be made as regards child health.

\section{ACKNOWLEDGEMENTS}

We wish to acknowledge Macro International Inc., for granting us permission to use data from the 2003 Nigerian

Demographic and Health Survey. We also acknowledge the contribution of Dr. Catherine Kyobutungi and Dr. Latifat Ibisomi who critically reviewed this paper for important intellectual content.

\section{ETHICAL APPROVAL}

This study involved secondary analysis of a public domain data set -NDHS 2003. Permission to use this data set was obtained in writing from Macro International Incorporation via the DHS website (www.measuredhs.com). The interview process via which the survey was conducted included the documentation of informed consent which was given by the respondents [8]. Respondent confidentiality is in tact as no names are included in the data set and therefore the respondents can not be traced by the researcher. Finally, the research protocol was submitted for review by Ethics Committee of the University of the Witwatersrand, Johannesburg-South Africa, and ethical clearance was obtained before the research began.

\section{AUTHORS' CONTRIBUTIONS}

SO did the data analysis, literature review and wrote the first draft of the manuscript and contributed to the interpretation of the findings.

CO conceptualized this study and contributed to the writing of the paper and interpretation of the findings. Both authors read and approved the final manuscript.

\section{REFERENCES}

[1] World Health Organisation. World Health Report. Neonatal \& Perinatal Mortality: Country, Regional and Global estimates. Geneva: WHO 2006.

[2] Wilkinson D. Reducing perinatal mortality in developing countries Health Policy Plan 1997; 12(2): 160-5.

[3] Richardus J, Graafmansp W, Verloove-Vanhorick S, Mackenbach J. The Perinatal Mortality Rate as an Indicator of Quality of Care in International Comparisons. Medical Care 1998; 36(1): 54-66.

[4] The United Nations. The Millenium Development Goals Report New York: UN 2006.

[5] Jose M, Paul IZB, Marjorie K, et al. Neonatal survival: a call for action. Lancet 2005; 365: 1189-97.

[6] Lawn J, Cousens S, Zupan J. 4 million deaths. When? Where? Why? Lancet 2005; 365: 891-900.

[7] World Health Organisation. Perinatal mortality: a listing of available information. Geneva: WHO 1996.

[8] National Population Commission [Nigeria], ORC Macro. Nigeria Demographic and Health Survey 2003: The Final Report. Calverton, MD: ORC Macro 2004.

[9] World Health Organisation. Health situation in the Americas: basic indicators. Washington DC: WHO 2006.

[10] Burnett C, Jones J, Rooks J, Chen C, Tyler CJ, Miller C. Home delivery and neonatal mortality in North Carolina. JAMA 1980; 244(24): 2741-5.

[11] Campbell R, Macdonald-Davies I, Macfarlane A, Beral V. Home births in England and Wales,1979: perinatal mortality according to intended place of delivery. BMJ 1984; 289: 721-4.

[12] Kaunitz M, Spence C, Danilson T, Rochat R, Grimas D. Perinatal mortality in a religious group avoiding obstetric care. American J Obstet Gynecol 1984; 150: 826-30.

[13] Parazzini F, LaVecchia C. Perinatal mortality and place of birth in Italy. Am J of Public Health 1988; 78(6): 706-7.

[14] Schramm W, Barnes D, Bakewell J. Neonatal mortality in Missouri home births, 1978-84. Am J Public Health 1987; 77(8): 930-5. 
[15] Durand AM. The safety of home births: The farm study. Am J Public Health 1992; 82(3): 450-3.

[16] Mcdermott J, Steketee R, Wirima J. Perinatal mortality in rural Malawi. Bull World Health Organ 1996; 74 (2): 165-71.

[17] Voorhoeve A, Kars C, Ginneken J. Modern and traditional antenatal and delivery care. In: van Ginneken JK, Muller AS, Eds. Maternal and Child health in Rural Kenya. Kent: Croom Helm 1985; pp. 309-22.

[18] Walraven G, Mkanje R, Roosmalen J, Van Dongen P, Dolmas W. Perinatal mortality in home births in rural Tanzania. Eur J Obstet Gynecol Reprod Biol 1995; 58: 131-4.

[19] Borrell C, Grera E, Ricart M, Pasarin M, Salvador J. Social Inequalities in Perinatal Mortality in a Southern European City. Eur J Epidemiol 2003; 18(1): 5-13.

[20] Forsass E, Gissler M, Sihvonen M, Hemminki E. Maternal predictors of perinatal mortality: the role of birthweight. Int J Epidemiol 1999; $28: 475-8$

[21] Golding J, Greenwood R, McCaw-Binns A, Thomas P. Associations between social and environmental factors and perinatal mortality in Jamaica. Paediatr Perinat Epidemiol 1994; 8(1): 17-39.

[22] Habib N, Lie R, Oneko O, Shao J, Bergsjø P, Daltveit A. Socio demographic characteristics and perinatal mortality among singletons in North East Tanzania: a registry-based study. J Epidemiol Commun Health 2008; 62: 960-5.

[23] Shah N, Shah M, Khalaf A, Mustafa M, Al-Sayed A. Searching for socioeconomic risk factors in perinatal mortality in Kuwait: a case- control study. Soc Sci Med 2000; 51: 539-50.

[24] Wessel H, Cnattingius S, Dupret A, Reitmaier PSB. Risk factors for perinatal deaths in Cape Verde. Paediatr Perinat Epidemiol 1998; 12(1): 25-36.

[25] World Health Organisation. Proportion of births attended by a skilled attendant: 2007 updates [Online]. Department of Reproductive Health and research, Geneva: WHO 2007. [cited 2007 August 21]. Available from: www.who.int/reproductive-health.

[26] Imogie A, Agwubike E, Aluko K. Assessing the role of Traditional Birth Attendants in Health Care delivery in Edo State, Nigeria. Afr J Rep Health 2002; 6(2): 94-100.

[27] Salako A, Daniel O. Identifying the training needs of Traditional Birth Attendants. Tropical Doctor 2007; 37: 6-10.

[28] Nielsen B, Liljestrand J, Hedegaard M, Thilsted S, Joseph A. Reproductive pattern, perinatal mortality, and sex preference in rural Tamil Nadu, south India: community based, cross sectional study. BMJ 1997; 314(7093): 1521-4.

[29] Wu Z, Viisainen K, Wang Y, Hemminki E. Perinatal mortality in rural China: a retrospective cohort. BMJ 2003; 327: 1319-22.

[30] Silins J, Semenciw M, Morrison H, et al. Risk factors for perinatal mortality in Canada. Can Med Assoc J 1985; 133(12): 1214-9.

[31] Weiner R, Ronsmans C, Dorman E, Jilo H, Muhoro A, Shulman C. Labour complications remain the most mportant risk factors for perinatal mortality in rural Kenya. Bull World Health Organ 2003; 81(8): 561-6.

Received: September 02, 2009

(C) Oti and Odimegwu; Licensee Bentham Open.

This is an open access article licensed under the terms of the Creative Commons Attribution Non-Commercial License (http://creativecommons.org/licenses/by-nc/3.0/) which permits unrestricted, non-commercial use, distribution and reproduction in any medium, provided the work is properly cited. 